\title{
Inputs and outputs of insulin receptor
}

\author{
Yipeng Du, Taotao Wei ${ }^{\bowtie}$ \\ National Laboratory of Biomacromolecules, Institute of Biophysics, Chinese Academy of Sciences, Beijing 100101, China \\ $\bowtie$ Correspondence: weitt@moon.ibp.ac.cn (T. Wei) \\ Received December 28, 2013 Accepted January 26, 2014
}

\begin{abstract}
The insulin receptor (IR) is an important hub in insulin signaling and its activation is tightly regulated. Upon insulin stimulation, IR is activated through autophosphorylation, and consequently phosphorylates several insulin receptor substrate (IRS) proteins, including IRS16, Shc and Gab1. Certain adipokines have also been found to activate IR. On the contrary, PTP, Grb and SOCS proteins, which are responsible for the negative regulation of IR, are characterized as IR inhibitors. Additionally, many other proteins have been identified as IR substrates and participate in the insulin signaling pathway. To provide a more comprehensive understanding of the signals mediated through IR, we reviewed the upstream and downstream signal molecules of IR, summarized the positive and negative modulators of IR, and discussed the IR substrates and interacting adaptor proteins. We propose that the molecular events associated with IR should be integrated to obtain a better understanding of the insulin signaling pathway and diabetes.
\end{abstract}

\section{KEYWORDS insulin, insulin receptor, signaling}

\section{INTRODUCTION}

Input and output are two basic concepts in the field of cellular signal transduction (Waltermann and Klipp, 2011). In general, the inputs of a signal transduction pathway are the upstream stimulation and inhibition signals, whereas the outputs are the downstream effects, such as the activation of substrates and interactions with other proteins. The classical insulin signaling pathway is initiated by the binding of insulin to the insulin receptor (IR) and the subsequent activation of insulin receptor substrate (IRS) proteins (Taniguchi et al., 2006). For the hub protein $I R$, the input is insulin, and the output is the phosphorylation of IRS proteins. However, the scenario is not as simple as this one-way signal transduction model. Recent progress in IR signaling indicated that insulin is not the only ligand for IR, and the phosphorylation of IRS proteins represents just one component of IR output. To provide a more complete understanding of the signals mediated through IR, we reviewed the inputs and outputs of IR in this study. We will first provide a brief description of the classical stimulus and substrates of IR and then mainly focus on the factors that positively and negatively regulate IR and the various IR substrates and interacting proteins.

\section{CLASSICAL INPUTS AND OUTPUTS OF IR}

The binding of insulin to the a subunits of IR heterotetramer is the main input into the insulin signaling pathway. The IR then undergoes a conformational change in its intracellular $\beta$ subunits that exposes its ATP-binding domain, which enables ATP binding and autophosphorylation. The output of IR activation is the phosphorylation of a group of IRS proteins (White and Kahn, 1994). IRS1 is the principal IRS protein and is phosphorylated at multiple tyrosine sites upon insulin stimulation (Sun et al., 1993). The tyrosine-phosphorylated IRS1 sites function by docking with $\mathrm{SH} 2$ domain-containing proteins and mediating signal transduction to various downstream factors. IRS2 is an alternative IR substrate that was discovered in IRS1-deficient mice (Patti et al., 1995). IRS1 and IRS2 are not functionally redundant, although they both activate many similar downstream pathways (Waters and Pessin, 1996; Hanke and Mann, 2009). IRS3 was first cloned in rat adipocytes and then in mouse. However, this homolog does not appear to exist in human cells (Lavan et al., 1997b; Sciacchitano and Taylor, 1997). IRS4 is the dominant IRS in HEK293 cells (Lavan et al., 1997a). Although IRS1 and IRS2 are present in the HEK293 cell line, they are not activated upon insulin stimulation (Fantin et al., 1998). These results indicate that the output of IR is tissue-specific. IRS5 and IRS6, also known as DOK4 and DOK5, are readily phos- 
A

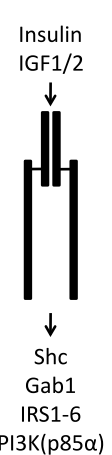

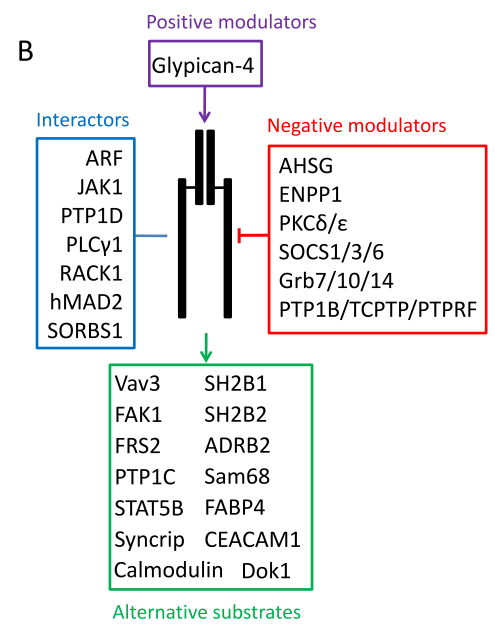

Figure 1. The diagram illustrating the inputs and outputs of insulin receptor. (A) Classical IR inputs and outputs. (B) Summary of proteins associating with IR which include positive modulator (purple), negative modulator (red), alternative substrates (green) and interactors (blue). Arrow: stimulation; Line: interaction; Arrow with flathead: inhibition.

phorylated in CHO-IR cells (Cai et al., 2003). IR-phosphorylated IRS5 binds to a number of SH2 domain-containing proteins, that are distinct from those associated with IRS1. However, IR-phosphorylated IRS6 does not bind to any SH2 domain-containing proteins, which indicates that it may mediate a different branch of the insulin signaling pathway (Cai et al., 2003). Shc interacts with and is phosphorylated by IR. Phosphorylated Shc can dock with Grb2 and mediate signal transduction through the Ras-MAPK signaling pathway (Sasaoka and Kobayashi, 2000). Gab1 is another IRS protein that is mainly involved in the PI3K-Akt pathway (Lehr et al., 2000). The p85a subunit of PI3K can be directly phosphorylated by IR after its docking to IRS1/2 (Hayashi et al., 1993; Van Horn et al., 1994). Although the classical IR inputs and outputs are simple and clear, they are only part of the story (Fig. 1A).

In addition to the classical IRS proteins, many other proteins have been shown to associate with $I R$ and to play a role in the insulin signaling pathway (Fig. 1B), which could be classified into four different types: (1) Positive modulators of IR (e.g., glypican-4 stimulates insulin function by binding to IR); (2) Negative modulators of IR [e.g., protein tyrosine phosphatases (PTPs), protein kinase C (PKC) isoforms, growth factor receptor-bound (Grb) and suppressors of cytokine signaling (SOCS) proteins]; (3) Alternative IR substrates involved in various biological processes; and (4) proteins that interact with IR, but are not its substrates. The following section will focus on these four types of proteins in an attempt to provide a complete description of the inputs and outputs of IR. The related proteins and references are summarized in Table 1.

\section{POSITIVE MODULATORS OF IR}

Insulin, IGF1 and IGF2 are traditional IR ligands. Some adipokines have also been found to interact with the IR a subunits and to enhance insulin sensitivity. Glypican-4, which is released from adipose tissue into the circulation, is a potential IR ligand. It binds to IR at regions different from that of insulin (Ussar et al., 2012). The depletion of glypican4 reduces insulin signaling, whereas the overexpression of wild-type glypican-4 enhances the insulin-mediated phosphorylation of ERK and AKT (Ussar et al., 2012), indicating its potential role as a target for the treatment of insulin resistance (Mitchell, 2012). Visfatin is related to the insulin signaling pathway, but its role in the stimulation of IR remains controversial (Adeghate, 2008).

\section{NEGATIVE MODULATORS OF IR}

The activity of IR is negatively regulated by several mechanisms. PTPs can dephosphorylate IR at autophosphorylated tyrosines and thus inactivate IR. Members of the PKC family phosphorylate serines near autophosphorylated tyrosine sites to disrupt the docking of $\mathrm{SH} 2$ domain-containing proteins. Proteins in the Grb and SCOS families bind directly to IR and block its interaction with downstream factors. In addition, other proteins, such as NEPP1 and AHSG, inhibit IR by interacting with its extracellular domain. This indicates that a variety of negative modulators of IR cooperate to inactivate IR. We here summarized the important negative modulators of IR.

\section{PTPs (PTP1B, PTP1C, TCPTP and PTPRF)}

PTPs are encoded by approximately 100 genes in humans (Alonso et al., 2004; Tonks, 2006). Classical PTPs dephosphorylate tyrosine phosphorylation to attenuate the function of many receptor tyrosine kinases (Andersen et al., 2001; Andersen et al., 2004). At least three PTPs proteins have been found to be involved in the negative regulation of IR by dephosphorylation. PTP1B is the best-known and moststudied PTP and regulates IR activity via dephosphorylation. It can be recruited to multiply tyrosine phosphorylation sites on the IR through its $\mathrm{SH} 2$ domain upon insulin stimulation and IR autophosphorylation (Seely et al., 1996). The tyrosines of PTP1B are then phosphorylated by IR, and this step greatly increases its dephosphorylation activity (Dadke et al., 2001). Phosphorylated PTP1B can dephosphorylate IR and inhibit its kinase activity (Salmeen et al., 2000). This typical negative feedback is widely present in biological processes. In addition, phosphorylated PTP1B can dephosphorylate itself to balance its catalytic activity. PTP1B has been recognized as a potential target for the enhancement of insulin sensitization through a series of functional studies (Delibegovic et al., 2007; Picardi et al., 2008; Delibegovic et al., 2009; Ma et al., 2011). Similar to PTP1B, TCPTP uses autophosphorylated IR as a direct substrate both in vivo and 
Table 1. Proteins associated with the inputs and outputs of insulin receptor

\begin{tabular}{|c|c|c|}
\hline Protein & Function & References \\
\hline \multicolumn{3}{|c|}{ Positive modulators } \\
\hline Glypican-4 & Binds IR $\alpha$ subunits. Facilitates insulin-induced formational change of IR & Ussar et al. 2012 \\
\hline \multicolumn{3}{|c|}{ Negative modulators } \\
\hline PTP1B & Major PTP involved in insulin signaling. Dephosphorylates IR tyrosine & Salmeen et al. 2000 \\
\hline TCPTP & Cooperates with PTP1B. Dephosphorylate IR tyrosine & Galic et al. 2003 \\
\hline PTPRF & Dephosphorylates IR tyrosine & Hashimoto et al. 1992 \\
\hline PKCठ & Predominant in muscle. Phosphorylates IR serine & Braiman et al. 2001 \\
\hline $\mathrm{PKC} \varepsilon$ & Predominant in liver. Phosphorylates IR serine & Samuel et al. 2007 \\
\hline Grb7 & Binds IR in vitro and in vivo & Kasus-Jacobi et al. 2000 \\
\hline Grb10 & Binds IR. Blocks IRS1/2 & Wick et al. 2003 \\
\hline Grb14 & Binds IR. Blocks PTP1B & Nouaille et al. 2006 \\
\hline socs1 & Binds IR. Interrupts IRS2 & Ueki et al. 2004 \\
\hline socs3 & Binds IR. Interrupts IRS1/2, STAT5B & Emanuelli et al. 2000 \\
\hline socs6 & Binds IR. Interrupts IRS1 & Mooney et al. 2001 \\
\hline ENPP1 & Binds IR $\alpha$ subunits. Inhibits insulin-induced conformational change of IR & Maddux and Goldfine, 2000 \\
\hline AHSG & Binds IR $\beta$ subunits extracellular region & Mathews et al. 2000 \\
\hline \multicolumn{3}{|c|}{ Alternative substrates } \\
\hline ADRB2 & Transmembrane protein. Phosphorylated by IR in vitro and in vivo & Baltensperger et al. 1996 \\
\hline Calmodulin & Calcium-dependent protein. Phosphorylated by IR in vitro and in vivo & Sacks et al. 1992 \\
\hline CEACAM1 & Transmembrane protein. Phosphorylated by IR in vitro and in vivo & Poy et al. $2002 a$ \\
\hline Dok1 & GAP-associated protein. Phosphorylated by IR in vitro and in vivo & Wick et al. 2001 \\
\hline FABP4 & Fatty acid-binding protein. Phosphorylated by IR in vitro & Buelt et al. 1991 \\
\hline FAK1 & Integrin signaling pathway. Phosphorylated by IR in vitro & Baron et al. 1998 \\
\hline FRS2 & FGFR substrate. Phosphorylated by IR in vitro & Delahaye et al. 2000 \\
\hline PTP1C & Protein tyrosine phosphatase. Phosphorylated by IR in vitro and in vivo & Uchida et al. 1994 \\
\hline SH2B1 & Interacts with IR and phosphorylated upon insulin stimulation in vivo & Kotani et al. 1998 \\
\hline $\mathrm{SH} 2 \mathrm{~B} 2$ & Interacts with IR and phosphorylated upon insulin stimulation in vivo & Moodie et al. 1999 \\
\hline STAT5B & Transcriptional factor. Phosphorylated by IR in vitro and in vivo & Chen et al. 1997 \\
\hline SYNCRIP & RNA-binding protein. Phosphorylated by IR in vitro & Hresko and Mueckler, 2002 \\
\hline Sam68 & RNA-binding protein. Phosphorylated by IR in vitro and in vivo & Sanchez-Margalet and Najib, 1999 \\
\hline Vav3 & Interacts with and phosphorylated by IR activation in vivo & Zeng et al. 2000 \\
\hline \multicolumn{3}{|c|}{ Proteins interacting with IR, but are not its substrates (Interactors) } \\
\hline ARF & Interacts with activated IR. PLD regulation & Shome et al. 1997 \\
\hline hMAD2 & Interacts with inactivated IR & O'Neill et al. 1997 \\
\hline JAK1 & Interacts with activated IR. Enhances IRS1 activation & Gual et al. 1998 \\
\hline PLCY1 & Interacts with activated IR. Enhances MAPK activation & Kwon et al. 2003 \\
\hline PTP1D & Interacts with activated IR. Enhances IRS1 activation & Kharitonenkov et al. 1995 \\
\hline RACK1 & Interacts with activated IR. Facilitates STAT3 activation & Zhang et al. 2006 \\
\hline SORBS1 & Interacts with inactivated IR & Lin et al. 2001 \\
\hline
\end{tabular}

in vitro (Lammers et al., 1993; Galic et al., 2003). Although both PTP1B and TCPTP inhibit the activity of IR by dephosphorylation, the catalytic tyrosine sites might be different. PTP1B prefers to tandem phosphorylate tyrosine, whereas TCPTP mainly catalyzes a single phosphorylated tyrosine (Galic et al., 2005). PTPRF, which is a 
transmembrane PTP, also interacts with and dephosphorylates IR in vitro and in vivo (Hashimoto et al., 1992; Ahmad and Goldstein, 1997). It can be deduced that PTP1B, TCPTP and PTPRF crosstalk with each other to negatively regulate IR. In summary, three PTPs can act as negative inputs to IR via tyrosine dephosphorylation under conditions of insulin stimulation.

\section{PKCs (PKCס and PKC $)$}

The PKC family consists of three distinct groups, namely, the classical, novel and atypical groups. In contrast to PTPs, which dephosphorylate proteins, PKCs function by phosphorylating serines or threonines. Several members in the PKC family have been shown to be involved in negatively regulating IR activity. In vitro-purified PKC can also phosphorylate IR and lower its tyrosine kinase activity (Bollag et al., 1986). In vivo studies using insulin-resistant human skeletal muscle suggest that PKCס is recruited to IR and reduces its activity via serine phosphorylation (Itani et al., 2000; Braiman et al., 2001; Rosenzweig et al., 2004). In insulin-resistant liver, $\mathrm{PKC} \varepsilon$ is the predominant activated PKC. PKCE inhibits insulin signaling by binding to IR and reducing its tyrosine kinase activity in hepatic steatosis (Samuel et al., 2007; Jornayvaz et al., 2011; Jornayvaz and Shulman, 2012). These studies indicate that PKC isoforms regulate IR activity in a tissue-specific manner. In addition, PKC can inhibit the insulin signaling pathway by phosphorylating other proteins in the insulin signaling pathway. For example, PKCO prefers IRS1 for phosphorylation (Griffin et al., 1999; Yu et al., 2002; Li et al., 2004). In summary, at least two PKCs act as negative inputs to IR via serine phosphorylation.

\section{Grb proteins (Grb10, Grb14 and Grb7)}

Unlike PTPs and PKC, which inhibit IR by covalently modification, Grb proteins reduce the activity of IR through direct interaction. The autophosphorylated tyrosine sites on IR not only dock IRS but also $\mathrm{SH} 2$ domain-containing proteins, which are not phosphorylated or activated by IR. These types of proteins compete with IRS for IR binding and then serve to inhibit IR activity. Grb10 was first found to be a high affinity interacting protein with IR in vitro (Liu and Roth, 1995). Further studies demonstrated that the Grb10 SH-2 domain and IR carboxyl catalytic active loop are required for this interaction (Hansen et al., 1996). Grb10 binds to the same domain as IRS1 on IR. This binding blocks the IRmediated phosphorylation of IRS1 and disrupts the IRS1PI3K signaling pathway (Wick et al., 2003). The biological role of Grb10 in promoting insulin signaling has been proven using a mouse model (Smith et al., 2007; Wang et al., 2007). Similar to Grb10, Grb14 binds to IR and blocks its autophosphorylation in a site-specific manner (Nouaille et al., 2006). The phenotypes of mice deficient in Grb14 and Grb10 differ, which indicates the non-redundant functions of these two proteins (Holt and Siddle, 2005). Grb7 is an additional Grb protein that participates in IR regulation. It binds to activated IR both in vitro and in vivo and may function in the same manner as Grb14 and Grb10 (Kasus-Jacobi et al., 2000). In summary, three Grb proteins can inhibit IR activity by directly blocking downstream signaling.

\section{SOCS proteins (SOCS1, SOCS3 and SOCS6)}

Initially identified as cytokine signaling inhibitors, SOCS proteins participate in various signal transduction pathways, including the insulin signaling pathway. Similar to Grb proteins, SOCS proteins directly interact with IR and block downstream signal transduction. For example, SOCS3 attenuates the IRSTAT5B signal branch by competing with STAT5B for binding to IR at phosphorylated tyrosine 960 (Emanuelli et al., 2000). SOCS3 also interrupts the IRS1 and IRS2 signal branch with the same mechanism (Ueki et al., 2004). Moreover, SOCS3 overexpression in cultured cells inhibits IR autophosphorylation. This mechanism is most likely mediated by crosstalk between IR regulators (Senn et al., 2003). In addition, SOCS3 is induced by STAT5B upon insulin stimulation (Emanuelli et al., 2000; Sadowski et al., 2001). This constitutes another negative feedback loop in the insulin signaling pathway. SOCS1 binds to IR on sites different from that of SOCS3, although they are both IR inhibitors (Mooney et al., 2001; Le et al., 2002; Ueki et al., 2004). SOCS6 binds to both IR and IRS4, which indicates that it inhibits the insulin signaling pathway by targeting multiple proteins (Mooney et al., 2001; Krebs et al., 2002). SOCS proteins can be induced by inflammation, which partially explains the role of inflammation in insulin resistance (Tanti et al., 2012; Suchy et al., 2013). We concluded that at least three SOCS proteins provide negative inputs to IR.

\section{ENPP1}

ENPP1 (ectonucleotide pyrophosphatase/phosphodiesterase family member 1 ) is a transmembrane protein with alkaline phosphodiesterase and nucleotide pyrophosphatase activity. However, its inhibition of IR autophosphorylation is independent of its enzymatic activity (Grupe et al., 1995). In contrast to Grb and SOCS proteins, which inhibit IR activity by interacting with its $\beta$ subunits, ENPP1 directly binds to the IR a subunits (Maddux and Goldfine, 2000). ENPP1 does not appear to affect insulin binding, but inhibits the insulin-induced conformational change of the IR $\alpha$ subunits (Maddux and Goldfine, 2000). The ENPP1 K173Q polymorphism (previously described as K121Q) has been associated with insulin resistance (Costanzo et al., 2001; McAteer et al., 2008; Moore et al., 2009) because the K173Q polymorphism tightly binds to IR and effectively inhibits IR. There are seven members in the ENPP family (Masse et al., 2010). Given the similarity between ENPP1 and the other ENPPs, particularly ENPP2 (Kato et al., 2012), it is possible that these other ENPPs may participate in the insulin signaling pathway. Furthermore, the up-regulation of ENPP2 
has been associated with insulin resistance in a diabetic mouse model (Boucher et al., 2005). Thus, it can be concluded that ENPP1 inhibits IR by blocking the conformational change of IR upon insulin binding.

\section{AHSG}

AHSG (alpha-2-Heremans-Schmid glycoprotein) inhibits the autophosphorylation of IR by interacting with the extracellular region of its $\beta$ subunits (Auberger et al., 1989; Srinivas et al., 1993; Mathews et al., 2000). The mechanism of this inhibition may be similar to that of ENPP1. AHSG is secreted by the liver and is released into the circulation. The blood levels of AHSG have been correlated with insulin resistance (Kalabay et al., 2002; Goustin and Abou-Samra, 2011). Thus, it is becoming clear that AHSG is another negative input of IR.

\section{ALTERNATIVE SUBSTRATES OF IR}

IR substrates are not restricted to the classical ones mentioned above. A variety of proteins have been found to be phosphorylated by activated IR. We categorized these proteins into different IR outputs and review their roles in the insulin signaling pathway in this section.

\section{ADRB2}

ADRB2 (beta-2-adrenergic receptor) is a member of the G-protein coupled receptor superfamily and can be phosphorylated by IR both in vivo and in vitro (Baltensperger et al., 1996). The phosphorylated tyrosine site on ADRB2 can recruit Grb2 and other proteins to promote the internalization of ADRB2 (Karoor et al., 1998). This indicates that the insulin signaling pathway may crosstalk with the GPCR (G-protein coupled receptor) signaling pathway.

\section{Calmodulin}

Calmodulin is a multifunctional calcium-dependent messenger protein that can be phosphorylated by different types of kinases, including IR (Laurino et al., 1988; Sacks and McDonald, 1988; Wong et al., 1988; Sacks et al., 1989; Sacks and McDonald, 1989; Sacks et al., 1992). The phosphorylation of calmodulin has an effect on its intrinsic enzyme property and on its downstream interacting proteins (Benaim and Villalobo, 2002). IR phosphorylates calmodulin at two major tyrosine sites, which attenuates its biological activity (Saville and Houslay, 1994; Williams et al., 1994; Sacks et al., 1995; Joyal et al., 1996). However, the precise role of this phosphorylation related to insulin signaling is unclear. Calmodulin may serve as a node for the crosstalk between the insulin signaling pathway and other signaling pathways.

\section{CEACAM1}

CEACAM1 (carcinoembryonic antigen-related cell adhesion molecule 1) is another transmembrane substrate of IR. IR phosphorylates CEACAM1 on its intracellular domain to initiate IR internalization (Formisano et al., 1995). CEACAM1-mediated IR internalization and degradation is important for insulin clearance in the liver (Poy et al., 2002b). The tyrosine-phosphorylated sites on CEACAM1 also compete with IR for Shc binding, thus attenuating IR signaling transduction to the MARK pathway (Poy et al., 2002a).

\section{Dok1}

Dok1 (docking protein 1) is phosphorylated by IR at specific tyrosine sites. Phosphorylated Dok1 enhances its binding to GAP, which is an inhibitor of RAS (Wick et al., 2001). Thus, RAS is dually regulated by the insulin signaling pathway: it is activated by Grb2-SOS and inactivated by Dok1-GAP. Dok2 and Dok3 do not appear to be related to the insulin signaling pathway, but these proteins interact with GAP and may play an important role in other pathways (Di Cristofano et al., 1998; Lemay et al., 2000).

\section{FABP4}

FABP4 (fatty acid-binding protein 4) is mainly expressed in adipocytes, which can be phosphorylated by the purified IR $\beta$ subunits in vitro (Buelt et al., 1991). In addition, results obtained from FABP4-deficient mice indicate that this protein may serve as a bridge linking obesity to insulin resistance (Hotamisligil et al., 1996). However, it remains unclear whether FABP4 is a substrate of IR in vivo and whether it participates in the insulin signaling pathway.

\section{FAK1}

FAK1 (focal adhesion kinase 1) is a cytosolic tyrosine kinase involved in integrin signaling. IR promotes FAK1 phosphorylation in suspended cells (Baron et al., 1998). In contrast, IR stimulates the dephosphorylation of FAK1 in attached cells (Pillay et al., 1995). The biological role of IR-phosphorylated FAK1 remains to be elucidated. The dual role of IR in FAK1 regulation may be related to the integrin-mediated signaling pathway.

\section{FRS2}

FRS2 (fibroblast growth factor receptor substrate 2) was originally found to be an adapter protein that links activated FGR receptors to the downstream signaling pathway ( $\mathrm{Xu}$ et al., 1998). It has also been revealed to be a direct substrate of IR in vitro and becomes tyrosine phosphorylated upon insulin stimulation in vivo (Delahaye et al., 2000).

\section{PTP1C}

PTP1C is able to bind to autophosphorylated IR and is phosphorylated by activated IR on its tyrosine residues (Uchida et al., 1994). In addition, the phosphatase activity of phosphorylated PTP1C increases. However, there is no 
evidence demonstrating that it can directly dephosphorylate IR, although PTP1C-deficient mice exhibit increased glucose tolerance and insulin sensitivity (Dubois et al., 2006).

\section{SH2B $1 / 2$}

SH2B1 and 2 are $\mathrm{SH} 2$ domain-containing proteins that can be tyrosine phosphorylated upon insulin stimulation (Yokouchi et al., 1997; Kotani et al., 1998; Wang and Riedel, 1998; Moodie et al., 1999). The insulin-induced phosphorylation of SH2B1/2 is potentially mediated by IR. Similar to Grb2 and Shc, phosphorylated SH2B1 and 2 may serve as a docking site for downstream factors. For example, phosphorylated SH2B2 can dock c-Cbl to IR and promote IR ubiquitination and internalization (Ahmed et al., 2000). In addition, SH2B 1 and 2 serve as an adaptor and substrates for other tyrosine kinase receptors, such as receptors of PDGF (platelet-derived growth factor), NGF (nerve growth factor), and FGF (fibroblast growth factor) (Rui and CarterSu, 1998; Kong et al., 2002; Wang et al., 2004).

\section{STAT5B}

STAT5B (signal transducer and activator of transcription 5B) has been demonstrated to be a direct substrate for IR both in vitro and in vivo (Chen et al., 1997; Sawka-Verhelle et al., 1997; Storz et al., 1999; Sawka-Verhelle et al., 2000). Phosphorylated STAT5B acts as a transcription factor and activates a series of target genes, including glucokinase and SOCS proteins (Sawka-Verhelle et al., 2000; Sadowski et al., 2001). Insulin-induced gene expression events may be partially mediated by STAT5B.

\section{SYNCRIP and Sam68}

IR substrates are not restricted to cytoplasmic enzymes and transcriptional factors. IR also phosphorylates RNA-binding proteins. For instance, the RNA-binding protein SYNCRIP (synaptotagmin-binding cytoplasmic RNA-interacting protein) is phosphorylated by IR in vitro (Hresko and Mueckler, 2000, 2002). Moreover, this phosphorylation can be disrupted by RNA binding. The RNA-binding protein Sam68, which can be induced by insulin, is phosphorylated by IR both in vitro and in vivo (Sanchez-Margalet and Najib, 1999; Sanchez-Margalet et al., 2003). Tyrosine-phosphorylated Sam68 (the $68 \mathrm{kDa}$ Src substrate associated during mitosis) can dock with p85 PI3K and GAP proteins (Sanchez-Margalet and Najib, 2001). The RNA-binding activity of Sam68 is also affected by tyrosine phosphorylation (Wang et al., 1995), indicating a role of the insulin signaling pathway in RNA metabolism.

\section{Vav3}

Vav3 is a member of the guanine nucleotide exchange factor family, which activates multiple pathways. Vav3 interacts with and is phosphorylated by IR when overexpressed in 293T cells (Zeng et al., 2000). IR-phosphorylated Vav3 promotes Rac-1 activation and actin cytoskeletal rearrangement and modulates the formation of cell membrane ruffles (Zeng et al., 2000).

\section{PROTEINS INTERACT WITH IR BUT ARE NOT ITS SUBSTRATES}

IR does not always provide an output signal via catalysis. Under certain conditions, signals from IR are transmitted by changes in its interaction status with its binding partners. For example, inactivated IR interacts with hMAD2 (human homolog of yeast MAD2) with high affinity. This interaction decreases upon IR activation (O'Neill et al., 1997). Similarly, SORBS1 (sorbin and SH3 domain-containing 1) dissociates from IR and binds to c-Abl upon insulin stimulation (Lin et al., 2001). Although the biological function of these types of proteins in the insulin signaling pathway remains unclear, they enable signal transduction through IR.

In cells overexpressing IR, JAK1 (Janus kinase 1) has been observed to interact with IR (Gual et al., 1998). In addition, the phosphorylation of both proteins is necessary for their interaction. The binding of JAK1 to IR may facilitate its catalytic activity to IRS1. RACK1 (receptor for activated C kinase 1) interacts with both IR and STAT3 in vitro. In addition, RACK1 mediates IR-induced STAT3 activation in vivo (Zhang et al., 2006). These results indicate that $I R$ transmits signals to STAT3 via RACK1. ARF (ADP-ribosylation factor) has been coimmunoprecipitated with activated IR and serves as an adaptor to IR-mediated PLD regulation (Shome et al., 1997). In addition, PTP1D (protein tyrosine phosphatase 1D), which is a member of the PTP family, can bind to both IR and IRS1 and enhance the docking of IRS1 to IR (Kharitonenkov et al., 1995). PLCY1 (phospholipase C gamma 1) can interact with activated IR in a SH2 domain-independent manner, which may be mediated by conformational changes of IR (Kwon et al., 2003). The binding to PLCY1 leads to phosphorylation, which plays a role in signal transduction to MAPK. Thus, the IR-mediated signals can be transmitted by interacting proteins independent of its catalytic activity.

\section{CONCLUSIONS}

After four decades of extensive investigation, a growing body of knowledge on IR has been accumulated. In this review, we summarized the signals input to or output from IR (Fig. 1). Although each signal branch through $I R$ is clear and understandable, the integration of all of the signal branches to obtain a full understanding of insulin signaling remains challenging. To fully understand the IR signaling cascades, it is not sufficient to study IR-interacting proteins or signal branches one-by-one; all related proteins and pathways must be integrated. The typical cellular response to insulin stimulation is the phosphorylation of classical IRS and IRSmediated macromolecular complex docking. However, we should consider other independently reported docking 
proteins, such as Dok1, SH2B1 and SH2B2 to the macromolecular docking process. In parallel with the docking event is the direct activation of a group of proteins, including calmodulin, STAT5B and SYNCRIP. We should also integrate the negative regulation mechanisms with the activation event triggered by IR. The represented members of negative regulators are PTPS, PKCs, Grb and SOCS proteins. In addition, insulin may be dissociated or internalized and degraded via a CEACAM-mediated mechanism. And there should be other IR related proteins and events which remain to be elucidated. Only if the input and output signals are integrated into one story, we may eventually obtain a full understanding of IR signaling.

\section{ACKNOWLEDGMENTS}

This work was supported by grants from the National Basic Research Program of China (2010CB833701) and the National Natural Science Foundation of China (Grant No. 31070736). The authors are indebted to Profs. Fuyu Yang and Pingsheng Liu (IBP, CAS) for helpful comments and suggestions.

\section{ABBREVIATIONS}

CEACAM1, carcinoembryonic antigen-related cell adhesion molecule 1; Dok1, docking protein 1; FABP4, fatty acid-binding protein 4; FRS2, fibroblast growth factor receptor substrate 2; Grb, growth factor receptor-bound; IR, insulin receptor; IRS, insulin receptor substrate; JAK1, Janus kinase 1; PKC, protein kinase C; PTP, protein tyrosine phosphatase; RACK1, receptor for activated C kinase 1; Sam68, the $68 \mathrm{kDa}$ Src substrate associated during mitosis; SOCS, suppressors of cytokine signaling; SORBS1, sorbin and $\mathrm{SH} 3$ domain-containing 1; STAT5B, signal transducer and activator of transcription 5B; SYNCRIP, synaptotagmin-binding cytoplasmic RNA-interacting protein.

\section{COMPLIANCE WITH ETHICS GUIDELINES}

Yipeng Du and Taotao Wei declare that they have no conflict of interest.

This article does not contain any studies with human or animal subjects performed by the any of the authors.

\section{OPEN ACCESS}

This article is distributed under the terms of the Creative Commons Attribution License which permits any use, distribution, and reproduction in any medium, provided the original author(s) and the source are credited.

\section{REFERENCES}

Adeghate E (2008) Visfatin: structure, function and relation to diabetes mellitus and other dysfunctions. Curr Med Chem 15:1851-1862

Ahmad F, Goldstein BJ (1997) Functional association between the insulin receptor and the transmembrane protein-tyrosine phosphatase LAR in intact cells. J Biol Chem 272:448-457
Ahmed Z, Smith BJ, Pillay TS (2000) The APS adapter protein couples the insulin receptor to the phosphorylation of $\mathrm{c}-\mathrm{Cbl}$ and facilitates ligand-stimulated ubiquitination of the insulin receptor. FEBS Lett 475:31-34

Alonso A, Sasin J, Bottini N, Friedberg I, Friedberg I, Osterman A, Godzik A, Hunter T, Dixon J, Mustelin T (2004) Protein tyrosine phosphatases in the human genome. Cell 117:699-711

Andersen JN, Mortensen OH, Peters GH, Drake PG, Iversen LF, Olsen $\mathrm{OH}$, Jansen PG, Andersen HS, Tonks NK, Moller NP (2001) Structural and evolutionary relationships among protein tyrosine phosphatase domains. Mol Cell Biol 21:71177136

Andersen JN, Jansen PG, Echwald SM, Mortensen OH, Fukada T, Del Vecchio R, Tonks NK, Moller NP (2004) A genomic perspective on protein tyrosine phosphatases: gene structure, pseudogenes, and genetic disease linkage. FASEB J 18:8-30

Auberger P, Falquerho L, Contreres JO, Pages G, Le Cam G, Rossi $B$, Le Cam A (1989) Characterization of a natural inhibitor of the insulin receptor tyrosine kinase: cDNA cloning, purification, and anti-mitogenic activity. Cell 58:631-640

Baltensperger K, Karoor V, Paul H, Ruoho A, Czech MP, Malbon CC (1996) The beta-adrenergic receptor is a substrate for the insulin receptor tyrosine kinase. J Biol Chem 271:1061-1064

Baron V, Calleja V, Ferrari P, Alengrin F, Van Obberghen E (1998) p125Fak focal adhesion kinase is a substrate for the insulin and insulin-like growth factor-I tyrosine kinase receptors. J Biol Chem 273:7162-7168

Benaim G, Villalobo A (2002) Phosphorylation of calmodulin. Functional implications. Eur J Biochem 269:3619-3631

Bollag GE, Roth RA, Beaudoin J, Mochly-Rosen D, Koshland DE Jr (1986) Protein kinase C directly phosphorylates the insulin receptor in vitro and reduces its protein-tyrosine kinase activity. Proc Natl Acad Sci USA 83:5822-5824

Boucher J, Quilliot D, Praderes JP, Simon MF, Gres S, Guigne C, Prevot D, Ferry G, Boutin JA, Carpene C et al (2005) Potential involvement of adipocyte insulin resistance in obesity-associated up-regulation of adipocyte lysophospholipase D/autotaxin expression. Diabetologia 48:569-577

Braiman L, Alt A, Kuroki T, Ohba M, Bak A, Tennenbaum T, Sampson SR (2001) Insulin induces specific interaction between insulin receptor and protein kinase $C$ delta in primary cultured skeletal muscle. Mol Endocrinol 15:565-574

Buelt MK, Shekels LL, Jarvis BW, Bernlohr DA (1991) In vitro phosphorylation of the adipocyte lipid-binding protein ( $p 15)$ by the insulin receptor. Effects of fatty acid on receptor kinase and substrate phosphorylation. J Biol Chem 266:12266-12271

Cai D, Dhe-Paganon S, Melendez PA, Lee J, Shoelson SE (2003) Two new substrates in insulin signaling, IRS5/DOK4 and IRS6/ DOK5. J Biol Chem 278:25323-25330

Chen J, Sadowski HB, Kohanski RA, Wang LH (1997) Stat5 is a physiological substrate of the insulin receptor. Proc Natl Acad Sci USA 94:2295-2300

Costanzo BV, Trischitta V, Di Paola R, Spampinato D, Pizzuti A, Vigneri R, Frittitta $L$ (2001) The $Q$ allele variant (GLN121) of membrane glycoprotein $\mathrm{PC}-1$ interacts with the insulin receptor and inhibits insulin signaling more effectively than the common $\mathrm{K}$ allele variant (LYS121). Diabetes 50:831-836 
Dadke S, Kusari A, Kusari J (2001) Phosphorylation and activation of protein tyrosine phosphatase (PTP) 1B by insulin receptor. Mol Cell Biochem 221:147-154

Delahaye L, Rocchi S, Van Obberghen E (2000) Potential involvement of FRS2 in insulin signaling. Endocrinology 141:621-628

Delibegovic M, Bence KK, Mody N, Hong EG, Ko HJ, Kim JK, Kahn BB, Neel BG (2007) Improved glucose homeostasis in mice with muscle-specific deletion of protein-tyrosine phosphatase 1B. Mol Cell Biol 27:7727-7734

Delibegovic M, Zimmer D, Kauffman C, Rak K, Hong EG, Cho YR, Kim JK, Kahn BB, Neel BG, Bence KK (2009) Liver-specific deletion of protein-tyrosine phosphatase 1B (PTP1B) improves metabolic syndrome and attenuates diet-induced endoplasmic reticulum stress. Diabetes 58:590-599

Di Cristofano A, Carpino N, Dunant N, Friedland G, Kobayashi R, Strife A, Wisniewski D, Clarkson B, Pandolfi PP, Resh MD (1998) Molecular cloning and characterization of p56dok-2 defines a new family of RasGAP-binding proteins. J Biol Chem 273:4827-4830

Dubois MJ, Bergeron S, Kim HJ, Dombrowski L, Perreault M, Fournes B, Faure R, Olivier M, Beauchemin N, Shulman GI et al (2006) The SHP-1 protein tyrosine phosphatase negatively modulates glucose homeostasis. Nat Med 12:549-556

Emanuelli B, Peraldi P, Filloux C, Sawka-Verhelle D, Hilton D, Van Obberghen E (2000) SOCS-3 is an insulin-induced negative regulator of insulin signaling. J Biol Chem 275:15985-15991

Fantin VR, Sparling JD, Slot JW, Keller SR, Lienhard GE, Lavan BE (1998) Characterization of insulin receptor substrate 4 in human embryonic kidney 293 cells. J Biol Chem 273:10726-10732

Formisano P, Najjar SM, Gross CN, Philippe N, Oriente F, Kern-Buell CL, Accili D, Gorden P (1995) Receptor-mediated internalization of insulin. Potential role of pp120/HA4, a substrate of the insulin receptor kinase. J Biol Chem 270:24073-24077

Galic S, Klingler-Hoffmann M, Fodero-Tavoletti MT, Puryer MA, Meng TC, Tonks NK, Tiganis T (2003) Regulation of insulin receptor signaling by the protein tyrosine phosphatase TCPTP. Mol Cell Biol 23:2096-2108

Galic S, Hauser C, Kahn BB, Haj FG, Neel BG, Tonks NK, Tiganis T (2005) Coordinated regulation of insulin signaling by the protein tyrosine phosphatases PTP1B and TCPTP. Mol Cell Biol 25:819-829

Goustin AS, Abou-Samra AB (2011) The "thrifty" gene encoding Ahsg/Fetuin-A meets the insulin receptor: Insights into the mechanism of insulin resistance. Cell Signal 23:980-990

Griffin ME, Marcucci MJ, Cline GW, Bell K, Barucci N, Lee D, Goodyear LJ, Kraegen EW, White MF, Shulman GI (1999) Free fatty acid-induced insulin resistance is associated with activation of protein kinase $\mathrm{C}$ theta and alterations in the insulin signaling cascade. Diabetes 48:1270-1274

Grupe A, Alleman J, Goldfine ID, Sadick M, Stewart TA (1995) Inhibition of insulin receptor phosphorylation by PC-1 is not mediated by the hydrolysis of adenosine triphosphate or the generation of adenosine. J Biol Chem 270:22085-22088

Gual P, Baron V, Lequoy V, Van Obberghen E (1998) Interaction of Janus kinases JAK-1 and JAK-2 with the insulin receptor and the insulin-like growth factor-1 receptor. Endocrinology 139:884-893

Hanke S, Mann M (2009) The phosphotyrosine interactome of the insulin receptor family and its substrates IRS-1 and IRS-2. Mol Cell Proteomics 8:519-534
Hansen H, Svensson U, Zhu J, Laviola L, Giorgino F, Wolf G, Smith RJ, Riedel H (1996) Interaction between the Grb10 SH2 domain and the insulin receptor carboxyl terminus. J Biol Chem 271:8882-8886

Hashimoto N, Feener EP, Zhang WR, Goldstein BJ (1992) Insulin receptor protein-tyrosine phosphatases. Leukocyte common antigen-related phosphatase rapidly deactivates the insulin receptor kinase by preferential dephosphorylation of the receptor regulatory domain. J Biol Chem 267:13811-13814

Hayashi H, Nishioka Y, Kamohara S, Kanai F, Ishii K, Fukui Y, Shibasaki F, Takenawa T, Kido H, Katsunuma N et al (1993) The alpha-type $85-\mathrm{kDa}$ subunit of phosphatidylinositol 3-kinase is phosphorylated at tyrosines 368,580 , and 607 by the insulin receptor. J Biol Chem 268:7107-7117

Holt LJ, Siddle K (2005) Grb10 and Grb14: enigmatic regulators of insulin action-and more? Biochem J 388:393-406

Hotamisligil GS, Johnson RS, Distel RJ, Ellis R, Papaioannou VE, Spiegelman BM (1996) Uncoupling of obesity from insulin resistance through a targeted mutation in aP2, the adipocyte fatty acid binding protein. Science 274:1377-1379

Hresko RC, Mueckler M (2000) A novel 68-kDa adipocyte protein phosphorylated on tyrosine in response to insulin and osmotic shock. J Biol Chem 275:18114-18120

Hresko RC, Mueckler M (2002) Identification of pp68 as the tyrosinephosphorylated form of SYNCRIP/NSAP1. A cytoplasmic RNAbinding protein. J Biol Chem 277:25233-25238

Itani SI, Zhou Q, Pories WJ, MacDonald KG, Dohm GL (2000) Involvement of protein kinase $\mathrm{C}$ in human skeletal muscle insulin resistance and obesity. Diabetes 49:1353-1358

Jornayvaz FR, Shulman GI (2012) Diacylglycerol activation of protein kinase Cepsilon and hepatic insulin resistance. Cell Metab 15:574-584

Jornayvaz FR, Birkenfeld AL, Jurczak MJ, Kanda S, Guigni BA, Jiang DC, Zhang D, Lee HY, Samuel VT, Shulman GI (2011) Hepatic insulin resistance in mice with hepatic overexpression of diacylglycerol acyltransferase 2. Proc Natl Acad Sci USA 108:5748-5752

Joyal JL, Crimmins DL, Thoma RS, Sacks DB (1996) Identification of insulin-stimulated phosphorylation sites on calmodulin. Biochemistry 35:6267-6275

Kalabay L, Cseh K, Pajor A, Baranyi E, Csakany GM, Melczer Z, Speer G, Kovacs M, Siller G, Karadi I et al (2002) Correlation of maternal serum fetuin/alpha2-HS-glycoprotein concentration with maternal insulin resistance and anthropometric parameters of neonates in normal pregnancy and gestational diabetes. Eur $\mathrm{J}$ Endocrinol 147:243-248

Karoor V, Wang L, Wang HY, Malbon CC (1998) Insulin stimulates sequestration of beta-adrenergic receptors and enhanced association of beta-adrenergic receptors with Grb2 via tyrosine 350 . J Biol Chem 273:33035-33041

Kasus-Jacobi A, Bereziat V, Perdereau D, Girard J, Burnol AF (2000) Evidence for an interaction between the insulin receptor and Grb7. A role for two of its binding domains, PIR and $\mathrm{SH} 2$. Oncogene 19:2052-2059

Kato K, Nishimasu H, Okudaira S, Mihara E, Ishitani R, Takagi J, Aoki J, Nureki O (2012) Crystal structure of Enpp1, an extracellular glycoprotein involved in bone mineralization and insulin signaling. Proc Natl Acad Sci USA 109:16876-16881 
Kharitonenkov A, Schnekenburger J, Chen Z, Knyazev P, Ali S, Zwick E, White M, Ullrich A (1995) Adapter function of proteintyrosine phosphatase 1D in insulin receptor/insulin receptor substrate-1 interaction. J Biol Chem 270:29189-29193

Kong M, Wang CS, Donoghue DJ (2002) Interaction of fibroblast growth factor receptor 3 and the adapter protein $\mathrm{SH} 2-\mathrm{B}$. A role in STAT5 activation. J Biol Chem 277:15962-15970

Kotani K, Wilden P, Pillay TS (1998) SH2-Balpha is an insulinreceptor adapter protein and substrate that interacts with the activation loop of the insulin-receptor kinase. Biochem J 335(Pt 1):103-109

Krebs DL, Uren RT, Metcalf D, Rakar S, Zhang JG, Starr R, De Souza DP, Hanzinikolas K, Eyles J, Connolly LM et al (2002) SOCS-6 binds to insulin receptor substrate 4, and mice lacking the SOCS-6 gene exhibit mild growth retardation. Mol Cell Biol 22:4567-4578

Kwon YK, Jang HJ, Kole S, He HJ, Bernier M (2003) Role of the pleckstrin homology domain of PLCgamma1 in its interaction with the insulin receptor. J Cell Biol 163:375-384

Lammers R, Bossenmaier B, Cool DE, Tonks NK, Schlessinger J, Fischer EH, Ullrich A (1993) Differential activities of protein tyrosine phosphatases in intact cells. J Biol Chem 268:22456-22462

Laurino JP, Colca JR, Pearson JD, DeWald DB, McDonald JM (1988) The in vitro phosphorylation of calmodulin by the insulin receptor tyrosine kinase. Arch Biochem Biophys 265:8-21

Lavan BE, Fantin VR, Chang ET, Lane WS, Keller SR, Lienhard GE (1997a) A novel 160-kDa phosphotyrosine protein in insulintreated embryonic kidney cells is a new member of the insulin receptor substrate family. J Biol Chem 272:21403-21407

Lavan BE, Lane WS, Lienhard GE (1997b) The 60-kDa phosphotyrosine protein in insulin-treated adipocytes is a new member of the insulin receptor substrate family. J Biol Chem 272:11439-11443

Le MN, Kohanski RA, Wang LH, Sadowski HB (2002) Dual mechanism of signal transducer and activator of transcription 5 activation by the insulin receptor. Mol Endocrinol 16:2764-2779

Lehr S, Kotzka J, Herkner A, Sikmann A, Meyer HE, Krone W, Muller-Wieland D (2000) Identification of major tyrosine phosphorylation sites in the human insulin receptor substrate Gab-1 by insulin receptor kinase in vitro. Biochemistry 39:10898-10907

Lemay S, Davidson D, Latour S, Veillette A (2000) Dok-3, a novel adapter molecule involved in the negative regulation of immunoreceptor signaling. Mol Cell Biol 20:2743-2754

Li Y, Soos TJ, Li X, Wu J, Degennaro M, Sun X, Littman DR, Birnbaum MJ, Polakiewicz RD (2004) Protein kinase C Theta inhibits insulin signaling by phosphorylating IRS1 at Ser(1101). J Biol Chem 279:45304-45307

Lin WH, Huang CJ, Liu MW, Chang HM, Chen YJ, Tai TY, Chuang LM (2001) Cloning, mapping, and characterization of the human sorbin and $\mathrm{SH} 3$ domain containing 1 (SORBS1) gene: a protein associated with c-Abl during insulin signaling in the hepatoma cell line Hep3B. Genomics 74:12-20

Liu F, Roth RA (1995) Grb-IR: a SH2-domain-containing protein that binds to the insulin receptor and inhibits its function. Proc Natl Acad Sci USA 92:10287-10291

Ma YM, Tao RY, Liu Q, Li J, Tian JY, Zhang XL, Xiao ZY, Ye F (2011) PTP1B inhibitor improves both insulin resistance and lipid abnormalities in vivo and in vitro. Mol Cell Biochem 357:65-72
Maddux BA, Goldfine ID (2000) Membrane glycoprotein PC-1 inhibition of insulin receptor function occurs via direct interaction with the receptor alpha-subunit. Diabetes 49:13-19

Masse K, Bhamra S, Allsop G, Dale N, Jones EA (2010) Ectophosphodiesterase/nucleotide phosphohydrolase (Enpp) nucleotidases: cloning, conservation and developmental restriction. Int J Dev Biol 54:181-193

Mathews ST, Chellam N, Srinivas PR, Cintron VJ, Leon MA, Goustin AS, Grunberger G (2000) Alpha2-HSG, a specific inhibitor of insulin receptor autophosphorylation, interacts with the insulin receptor. Mol Cell Endocrinol 164:87-98

McAteer JB, Prudente S, Bacci S, Lyon HN, Hirschhorn JN, Trischitta V, Florez JC, Consortium E (2008) The ENPP1 $\mathrm{K} 121 \mathrm{Q}$ polymorphism is associated with type 2 diabetes in European populations: evidence from an updated meta-analysis in 42, 042 subjects. Diabetes 57:1125-1130

Mitchell F (2012) Obesity: glypican-4: role in insulin signalling. Nat Rev Endocrinol 8:505

Moodie SA, Alleman-Sposeto J, Gustafson TA (1999) Identification of the APS protein as a novel insulin receptor substrate. J Biol Chem 274:11186-11193

Mooney RA, Senn J, Cameron S, Inamdar N, Boivin LM, Shang Y, Furlanetto RW (2001) Suppressors of cytokine signaling-1 and -6 associate with and inhibit the insulin receptor. A potential mechanism for cytokine-mediated insulin resistance. J Biol Chem 276:25889-25893

Moore AF, Jablonski KA, Mason CC, McAteer JB, Arakaki RF, Goldstein BJ, Kahn SE, Kitabchi AE, Hanson RL, Knowler WC et al (2009) The association of ENPP1 K121Q with diabetes incidence is abolished by lifestyle modification in the diabetes prevention program. J Clin Endocrinol Metab 94:449-455

Nouaille S, Blanquart C, Zilberfarb V, Boute N, Perdereau D, Roix J, Burnol AF, Issad T (2006) Interaction with Grb14 results in sitespecific regulation of tyrosine phosphorylation of the insulin receptor. EMBO Rep 7:512-518

O'Neill TJ, Zhu Y, Gustafson TA (1997) Interaction of MAD2 with the carboxyl terminus of the insulin receptor but not with the IGFIR. Evidence for release from the insulin receptor after activation. J Biol Chem 272:10035-10040

Patti ME, Sun XJ, Bruening JC, Araki E, Lipes MA, White MF, Kahn CR (1995) 4PS/insulin receptor substrate (IRS)-2 is the alternative substrate of the insulin receptor in IRS-1-deficient mice. J Biol Chem 270:24670-24673

Picardi PK, Calegari VC, Prada PO, Moraes JC, Araujo E, Marcondes MC, Ueno M, Carvalheira JB, Velloso LA, Saad MJ (2008) Reduction of hypothalamic protein tyrosine phosphatase improves insulin and leptin resistance in diet-induced obese rats. Endocrinology 149:3870-3880

Pillay TS, Sasaoka T, Olefsky JM (1995) Insulin stimulates the tyrosine dephosphorylation of pp125 focal adhesion kinase. J Biol Chem 270:991-994

Poy MN, Ruch RJ, Fernstrom MA, Okabayashi Y, Najjar SM (2002a) Shc and CEACAM1 interact to regulate the mitogenic action of insulin. J Biol Chem 277:1076-1084

Poy MN, Yang Y, Rezaei K, Fernstrom MA, Lee AD, Kido Y, Erickson SK, Najjar SM (2002b) CEACAM1 regulates insulin clearance in liver. Nat Genet 30:270-276 
Rosenzweig T, Aga-Mizrachi S, Bak A, Sampson SR (2004) Src tyrosine kinase regulates insulin-induced activation of protein kinase C (PKC) delta in skeletal muscle. Cell Signal 16:1299-1308

Rui L, Carter-Su C (1998) Platelet-derived growth factor (PDGF) stimulates the association of SH2-Bbeta with PDGF receptor and phosphorylation of SH2-Bbeta. J Biol Chem 273:21239-21245

Sacks DB, McDonald JM (1988) Insulin-stimulated phosphorylation of calmodulin by rat liver insulin receptor preparations. J Biol Chem 263:2377-2383

Sacks DB, McDonald JM (1989) Calmodulin as substrate for insulinreceptor kinase. Phosphorylation by receptors from rat skeletal muscle. Diabetes 38:84-90

Sacks DB, Fujita-Yamaguchi Y, Gale RD, McDonald JM (1989) Tyrosine-specific phosphorylation of calmodulin by the insulin receptor kinase purified from human placenta. Biochem $\mathrm{J}$ 263:803-812

Sacks DB, Davis HW, Crimmins DL, McDonald JM (1992) Insulinstimulated phosphorylation of calmodulin. Biochem J 286(Pt 1):211-216

Sacks DB, Mazus B, Joyal JL (1995) The activity of calmodulin is altered by phosphorylation: modulation of calmodulin function by the site of phosphate incorporation. Biochem J 312(Pt 1):197204

Sadowski CL, Choi TS, Le M, Wheeler TT, Wang LH, Sadowski HB (2001) Insulin Induction of SOCS-2 and SOCS-3 mRNA expression in C2C12 Skeletal Muscle Cells Is Mediated by Stat5*. J Biol Chem 276:20703-20710

Salmeen A, Andersen JN, Myers MP, Tonks NK, Barford D (2000) Molecular basis for the dephosphorylation of the activation segment of the insulin receptor by protein tyrosine phosphatase 1B. Mol Cell 6:1401-1412

Samuel VT, Liu ZX, Wang A, Beddow SA, Geisler JG, Kahn M, Zhang XM, Monia BP, Bhanot S, Shulman GI (2007) Inhibition of protein kinase Cepsilon prevents hepatic insulin resistance in nonalcoholic fatty liver disease. J Clin Invest 117:739-745

Sanchez-Margalet V, Najib S (1999) p68 Sam is a substrate of the insulin receptor and associates with the $\mathrm{SH} 2$ domains of $\mathrm{p} 85$ PI3K. FEBS Lett 455:307-310

Sanchez-Margalet V, Najib S (2001) Sam68 is a docking protein linking GAP and PI3K in insulin receptor signaling. Mol Cell Endocrinol 183:113-121

Sanchez-Margalet V, Gonzalez-Yanes C, Najib S, FernandezSantos JM, Martin-Lacave I (2003) The expression of Sam68, a protein involved in insulin signal transduction, is enhanced by insulin stimulation. Cell Mol Life Sci 60:751-758

Sasaoka T, Kobayashi M (2000) The functional significance of Shc in insulin signaling as a substrate of the insulin receptor. Endocr $\mathrm{J}$ 47:373-381

Saville MK, Houslay MD (1994) Phosphorylation of calmodulin on Tyr99 selectively attenuates the action of calmodulin antagonists on type-I cyclic nucleotide phosphodiesterase activity. Biochem J 299(Pt 3):863-868

Sawka-Verhelle D, Filloux C, Tartare-Deckert S, Mothe I, Van Obberghen $E$ (1997) Identification of Stat 5B as a substrate of the insulin receptor. Eur J Biochem 250:411-417

Sawka-Verhelle D, Tartare-Deckert S, Decaux JF, Girard J, Van Obberghen E (2000) Stat $5 B$, activated by insulin in a Jak- independent fashion, plays a role in glucokinase gene transcription. Endocrinology 141:1977-1988

Sciacchitano S, Taylor SI (1997) Cloning, tissue expression, and chromosomal localization of the mouse IRS-3 gene. Endocrinology 138:4931-4940

Seely BL, Staubs PA, Reichart DR, Berhanu P, Milarski KL, Saltiel AR, Kusari J, Olefsky JM (1996) Protein tyrosine phosphatase 1B interacts with the activated insulin receptor. Diabetes 45:13791385

Senn JJ, Klover PJ, Nowak IA, Zimmers TA, Koniaris LG, Furlanetto RW, Mooney RA (2003) Suppressor of cytokine signaling-3 (SOCS-3), a potential mediator of interleukin-6-dependent insulin resistance in hepatocytes. J Biol Chem 278:13740-13746

Shome K, Vasudevan C, Romero G (1997) ARF proteins mediate insulindependent activation of phospholipase D. Curr Biol 7:387-396

Smith FM, Holt LJ, Garfield AS, Charalambous M, Koumanov F, Perry M, Bazzani R, Sheardown SA, Hegarty BD, Lyons RJ et al (2007) Mice with a disruption of the imprinted Grb10 gene exhibit altered body composition, glucose homeostasis, and insulin signaling during postnatal life. Mol Cell Biol 27:5871-5886

Srinivas PR, Wagner AS, Reddy LV, Deutsch DD, Leon MA, Goustin AS, Grunberger G (1993) Serum alpha 2-HS-glycoprotein is an inhibitor of the human insulin receptor at the tyrosine kinase level. Mol Endocrinol 7:1445-1455

Storz P, Doppler H, Pfizenmaier K, Muller G (1999) Insulin selectively activates STAT5b, but not STAT5a, via a JAK2independent signalling pathway in Kym-1 rhabdomyosarcoma cells. FEBS Lett 464:159-163

Suchy D, Labuzek K, Machnik G, Kozlowski M, Okopien B (2013) SOCS and diabetes-ups and downs of a turbulent relationship. Cell Biochem Funct 31:181-195

Sun XJ, Crimmins DL, Myers MG Jr, Miralpeix M, White MF (1993) Pleiotropic insulin signals are engaged by multisite phosphorylation of IRS-1. Mol Cell Biol 13:7418-7428

Taniguchi CM, Emanuelli B, Kahn CR (2006) Critical nodes in signalling pathways: insights into insulin action. Nat Rev Mol Cell Biol 7:85-96

Tanti JF, Ceppo F, Jager J, Berthou F (2012) Implication of inflammatory signaling pathways in obesity-induced insulin resistance. Front Endocrinol (Lausanne) 3:181

Tonks NK (2006) Protein tyrosine phosphatases: from genes, to function, to disease. Nat Rev Mol Cell Biol 7:833-846

Uchida T, Matozaki T, Noguchi T, Yamao T, Horita K, Suzuki T, Fujioka Y, Sakamoto C, Kasuga M (1994) Insulin stimulates the phosphorylation of Tyr538 and the catalytic activity of PTP1C, a protein tyrosine phosphatase with Src homology-2 domains. J Biol Chem 269:12220-12228

Ueki K, Kondo T, Kahn CR (2004) Suppressor of cytokine signaling 1 (SOCS-1) and SOCS-3 cause insulin resistance through inhibition of tyrosine phosphorylation of insulin receptor substrate proteins by discrete mechanisms. Mol Cell Biol 24:5434-5446

Ussar S, Bezy O, Bluher M, Kahn CR (2012) Glypican-4 enhances insulin signaling via interaction with the insulin receptor and serves as a novel adipokine. Diabetes 61:2289-2298

Van Horn DJ, Myers MG Jr, Backer JM (1994) Direct activation of the phosphatidylinositol 3'-kinase by the insulin receptor. J Biol Chem 269:29-32 
Waltermann C, Klipp E (2011) Information theory based approaches to cellular signaling. Biochim Biophys Acta 1810:924-932

Wang J, Riedel H (1998) Insulin-like growth factor-I receptor and insulin receptor association with a Src homology-2 domaincontaining putative adapter. J Biol Chem 273:3136-3139

Wang LL, Richard S, Shaw AS (1995) P62 association with RNA is regulated by tyrosine phosphorylation. J Biol Chem 270:2010-2013

Wang X, Chen L, Maures TJ, Herrington J, Carter-Su C (2004) SH2$B$ is a positive regulator of nerve growth factor-mediated activation of the Akt/Forkhead pathway in PC12 cells. J Biol Chem 279:133-141

Wang L, Balas B, Christ-Roberts CY, Kim RY, Ramos FJ, Kikani CK, Li C, Deng C, Reyna S, Musi N et al (2007) Peripheral disruption of the Grb10 gene enhances insulin signaling and sensitivity in vivo. Mol Cell Biol 27:6497-6505

Waters SB, Pessin JE (1996) Insulin receptor substrate 1 and 2 (IRS1 and IRS2): what a tangled web we weave. Trends Cell Biol 6:1-4

White MF, Kahn CR (1994) The insulin signaling system. J Biol Chem 269:1-4

Wick MJ, Dong LQ, Hu D, Langlais P, Liu F (2001) Insulin receptormediated p62dok tyrosine phosphorylation at residues 362 and 398 plays distinct roles for binding GTPase-activating protein and Nck and is essential for inhibiting insulin-stimulated activation of Ras and Akt. J Biol Chem 276:42843-42850

Wick KR, Werner ED, Langlais P, Ramos FJ, Dong LQ, Shoelson SE, Liu F (2003) Grb10 inhibits insulin-stimulated insulin receptor substrate (IRS)-phosphatidylinositol 3-kinase/Akt signaling pathway by disrupting the association of IRS-1/IRS-2 with the insulin receptor. J Biol Chem 278:8460-8467
Williams JP, Jo H, Sacks DB, Crimmins DL, Thoma RS, Hunnicutt RE, Radding W, Sharma RK, McDonald JM (1994) Tyrosinephosphorylated calmodulin has reduced biological activity. Arch Biochem Biophys 315:119-126

Wong EC, Sacks DB, Laurino JP, McDonald JM (1988) Characteristics of calmodulin phosphorylation by the insulin receptor kinase. Endocrinology 123:1830-1836

Xu H, Lee KW, Goldfarb M (1998) Novel recognition motif on fibroblast growth factor receptor mediates direct association and activation of SNT adapter proteins. J Biol Chem 273:17987-17990

Yokouchi M, Suzuki R, Masuhara M, Komiya S, Inoue A, Yoshimura A (1997) Cloning and characterization of APS, an adaptor molecule containing $\mathrm{PH}$ and $\mathrm{SH} 2$ domains that is tyrosine phosphorylated upon B-cell receptor stimulation. Oncogene 15:7-15

Yu C, Chen Y, Cline GW, Zhang D, Zong H, Wang Y, Bergeron R, Kim JK, Cushman SW, Cooney GJ et al (2002) Mechanism by which fatty acids inhibit insulin activation of insulin receptor substrate-1 (IRS-1)-associated phosphatidylinositol 3-kinase activity in muscle. J Biol Chem 277:50230-50236

Zeng L, Sachdev P, Yan L, Chan JL, Trenkle T, McClelland M, Welsh J, Wang LH (2000) Vav3 mediates receptor protein tyrosine kinase signaling, regulates GTPase activity, modulates cell morphology, and induces cell transformation. Mol Cell Biol 20:9212-9224

Zhang W, Zong CS, Hermanto U, Lopez-Bergami P, Ronai Z, Wang LH (2006) RACK1 recruits STAT3 specifically to insulin and insulin-like growth factor 1 receptors for activation, which is important for regulating anchorage-independent growth. Mol Cell Biol 26:413-424 